\title{
Endogenous Timing in Contests with Group-Specific Public-Goods Prizes
}

\author{
Jong Hwa Lee \\ Korea Institute for Defense Analyses, Seoul, South Korea \\ Email: jonghwa31@kida.re.kr
}

How to cite this paper: Lee, J.H. (2017) Endogenous Timing in Contests with GroupSpecific Public-Goods Prizes. Theoretical Economics Letters, 7, 1660-1666. https://doi.org/10.4236/tel.2017.76112

Received: August 15, 2017

Accepted: September 26, 2017

Published: September 29, 2017

Copyright $\odot 2017$ by author and Scientific Research Publishing Inc. This work is licensed under the Creative Commons Attribution International License (CC BY 4.0).

http://creativecommons.org/licenses/by/4.0/

\begin{abstract}
I analyze the two-group contest with the group-specific public-goods prize when each player decides on the timing of their moves endogenously and individually. Unlike the previous papers, I show that free riders suffer a damage in the endogenous-timing framework because the decision on the endogenous timing adversely affects the behavior of free riders, by making them more egotistical.
\end{abstract}

\section{Keywords}

Group-Specific Public-Goods Prize, Endogenous Timing, Free-Rider Problem

\section{Introduction}

The free rider problem often occurs when players voluntarily exert effort to obtain public goods, which has non-rival and non-excludable properties. Free riders attempt to gain benefits from public goods without exerting effort. A larger literature on the voluntary provision of public goods has emerged to analyze the sequential contribution mechanism. The main question is why players including free riders prefer to contribute sequentially, even though this mechanism does little to alleviate a free-rider problem. The suggested possibilities include exerting lower effort levels [1], existing a fixed cost [2], having additional effects as warm-grow or snob appealing [3].

The free-rider problem arises not only from public goods provision in a group but also from between-group competition for obtaining public goods. The theory of contests with the group-specific public-goods prize considers the free-rider problem in group contest ${ }^{1}$. Most of the papers examine the situation in which ${ }^{1}$ Group contests with group-specific public-goods prizes are easily observed; for example, R \& Dresearch and development-competitions among firms, competitions for the public good between local governments, and election campaigns between political parties. 
players having the different valuations for the public good compete with each other by exerting effort simultaneously [4] [5] [6] [7] [8]. Even in betweengroup competition with the group-specific public-goods prize, do players prefer to exert effort sequentially rather than simultaneously?

Drawing on contest theory, all players obtain a strategic advantage when they choose the timing of moves endogenously. Players who move earlier employ a strategic advantage, whereas players who move later efficiently manage their strategies by observing the preceding move of the players [9] [10] [11] [12]. For this reason, one may intuitively explain that both players exerting a positive effort and free riders can benefit by the choice of endogenous timing.

I, therefore, examine how all players in two groups are affected when they endogenously decide on strategies regarding the timing of moves, particularly with regard to group-specific public-goods prizes. I first describe the endogenoustiming framework, in which each player decides on the timing of moves endogenously, and then compare the expected payoffs in the endogenous-timing framework with those in the simultaneous-move framework, in which all players exert effort simultaneously. I show that free riders indirectly suffer damages in the endogenous-timing framework, compared with the simultaneous-move framework.

\section{Model}

Two groups compete with each other to obtain the group-specific public-goods prize. Group $i$ consists of $n_{i}$ risk-neutral players, where $n_{i} \geq 2$ for $i=1$ or 2 . The individual player's valuation for the public good is different and announced publicly. Let $v_{i k}$ denote the valuation of the public good of player $k$ in group $i$.

Assumption 1. Without loss of generality, I assume that

$v_{i 1}>v_{i 2}>\cdots>v_{i n_{i}}>0$.

All individual players decide on the timing of their moves, which is composed of two periods: the first and second periods. However, they cannot exert effort in both periods. The subgroup in which the players choose the period $t$ in group $i$ is denoted by $G_{i}^{t}$. Let $x_{i k}^{t}$ represent the effort level exerted by player $k$ in $G_{i}^{t}$, which is nonnegative and nonrefundable; let $X_{i}^{t}$ represent $G_{i}^{t}$ 's total effort levels, $X_{i}^{t}=\sum_{k \in G_{i}^{t}} X_{i k}^{t}$; and let $X_{i}$ represent the total effort levels of group $i$, $X_{i}=\sum_{t=1}^{2} X_{i}^{t}$. I define the winning probability for group $i$ as $P_{i}=P_{i}\left(X_{1}, X_{2}\right)$ where $1 \geq P_{i} \geq 0, \sum_{i=1}^{2} P_{i}=1$. The winning probability for group $i$ has the properties described in Assumption 2.

Assumption 2. I assume that $\partial P_{i} / \partial X_{i}>0, \partial^{2} P_{i} / \partial X_{i}^{2}<0$ when $X_{j}>0$, and $\partial P_{i} / \partial X_{j}<0, \partial^{2} P_{i} / \partial X_{j}^{2}>0$ when $X_{i}>0, i \neq j$.

Assumption 2 indicates that the winning probability of group $i$ is increasing and strictly concave in group $i$ 's effort ${ }^{2}$. Let $\pi_{i k}^{t}$ represent the expected payoff of ${ }^{2} \mathrm{~A}$ simple example of the contest success function is

$$
\begin{aligned}
P_{i} & =X_{i} / X_{i}+X_{j} & & \text { if } X_{i}+X_{j}>0, \\
& =1 / 2 & & \text { if } X_{i}+X_{j}=0 .
\end{aligned}
$$

This simple logit function is introduced in Tullock (1980) and is used in many works on contest theory. 
player $k$ in $G_{i}^{t}$. The expected payoff for player $k$ in $G_{i}^{t}$ becomes

$$
\pi_{i k}^{t}=v_{i k} P_{i}\left(X_{1}, X_{2}\right)-x_{i k}^{t} \text {. }
$$

I formally organize the paper as follows. In the announcement stage, each player independently decides whether to exert effort in the first or second periods. After choosing the period, the players announce and commit to their choices simultaneously. In the effort stage, knowing when the players exert their effort, each player sequentially and independently exerts effort in the period decided in the announcement stage. The winning group is determined at the end of the effort stage. Finally, I assume that all of the above is common knowledge among all players, and employ a subgame-perfect equilibrium as the solution concept.

\section{Players' Decisions in the Effort Stage}

To obtain subgame-perfect equilibria, I work backward from the second period in the effort stage. Given other players' effort levels, $X_{i}^{1}$ and $X_{j}$, player $k$ in $G_{i}^{2}$ exerts effort $x_{i k}^{2}$ by maximizing his expected payoff (1). The first-order condition for player $k$ in $G_{i}^{2}$ becomes

$$
v_{i k}\left(\partial P_{i} / \partial x_{i k}^{2}\right)-1=v_{i k}\left(\partial P_{i} / \partial X_{i}\right)\left(\partial X_{i} / \partial x_{i k}^{2}\right)-1 \leq 0 .
$$

The second-order condition is satisfied, which means that the best response of player $k$ in $G_{i}^{2}$ is unique. Assuming that player $k$ has the highest-valuation for the public good among the players in $G_{i}^{2}$, the marginal gross payoff for player $k, v_{i k}\left(\partial P_{i} / \partial x_{i k}^{2}\right)$, becomes high enough to satisfy the condition among the players in $G_{i}^{2}$. However, the players without player $k$ obtain a negative expected payoff when exerting a positive effort, as the marginal gross payoff for them is less than the marginal cost from Assumptions 1 and 3. In the second period, only the highest-valuation player $k$ thus becomes the active player, whereas the rest act as free riders in $G_{i}^{2}$. The $G_{i}^{2}$ 's best response to the effort levels of both $G_{i}^{1}$ and group $j$ is equal to the active player $k$ 's best response when considering the valuation for the active player $k$ in $G_{i}^{2}$. Given $X_{i}^{1}$ and $X_{j}$, I represent the best response of the active player $k$ in $G_{i}^{2}$ as $X_{i k}^{B 2}\left(X_{i}^{1}, X_{j} ; v_{i k}\right)$. The best response of the active player $k$ in $G_{i}^{2}$ turns into

$$
\begin{cases}x_{i k}^{B 2}\left(X_{i}^{1}, X_{j} ; v_{i k}\right)>0 & \text { if } v_{i k} \partial P_{i} / \partial x_{i k}^{2}=1, \\ x_{i k}^{B 2}\left(X_{i}^{1}, X_{j} ; v_{i k}\right)=0 & \text { if } v_{i k} \partial P_{i} / \partial x_{i k}^{2}<1 .\end{cases}
$$

The players announcing the first period have perfect foresight about their expected payoffs. They make their strategic decisions by considering the best response of $G_{i}^{2}$. The players in $G_{i}^{1}$ exert effort, which maximizes (1). The firstorder condition for player $h$ in $G_{i}^{1}$ becomes

$$
v_{i h} \partial P_{i} / \partial x_{i h}^{1}-1=v_{i h}\left(\partial P_{i} / \partial X_{i}^{1}\right)\left(\partial X_{i}^{1} / \partial x_{i h}^{1}\right)-1 \leq 0 .
$$

The second-order condition is also satisfied. Since the analysis is similar to the strategic behavior of the players in $G_{i}^{2}$, only the highest-valuation player $h$ who 
has the highest-valuation in $G_{i}^{1}$ becomes the active player, whereas the rest become free riders in $G_{i}^{1}$. The $G_{i}^{1}$ 's best response to group $j$ also becomes the active player $h$ 's best response when considering his valuation and the active players' valuations in the second period. Let $x_{i h}^{B 1}\left(X_{j} ; v_{i h}, v_{i k}, v_{j k}\right)$ denote the best responses for the active player $h$ in $G_{i}^{1}$, then

$$
\begin{cases}x_{i h}^{B 1}\left(X_{j} ; v_{i h}, v_{i k}, v_{j k}\right)>0 & \text { if } v_{i h} \partial P_{i} / \partial x_{i h}^{1}=1, \\ x_{i h}^{B 1}\left(X_{j} ; v_{i h}, v_{i k}, v_{j k}\right)=0 & \text { if } v_{i h} \partial P_{i} / \partial x_{i h}^{1}<1 .\end{cases}
$$

Using the best responses for active players in each period, $x_{i h}^{B 1}\left(X_{j} ; v_{i h}, v_{i k}, v_{j k}\right)$ and $x_{i k}^{B 2}\left(X_{i}^{1}, X_{j} ; v_{i k}\right)$, I obtain Lemma 1.

Lemma 1. In each group, player 1 with the highest-valuation becomes the active player, and the others become the free riders when all the players choose the timing of moves endogenously.

Whenever player 1 announces the first or second periods, the marginal gross payoff for another active player in the other period is less than the marginal cost. He also freely rides on player 1 .

\section{Timing Decision in the Announcement Stage}

Assuming that $v_{11}>v_{21}$, player 1 in group 1 acts as a favorite, whose winning probability is greater than $1 / 2$, and player 1 in group 2 becomes an underdog, whose winning probability is less than $1 / 2$ [13]. Drawing on the contest theory, player 1 in group 2, as the underdog, has a dominant strategy of announcing the first period, whereas player 1 in group 1, as the favorite, prefers to announce the second period ${ }^{3}$. Free riders, however, have no dominant strategies for choosing their timing of moves, since they obtain the same expected payoff in any period. Let $x_{i k}^{*}$ denote the equilibrium effort level for player $k$ in group $i$, and let $x_{-i k}^{*}$ denote a vector of the equilibrium effort levels for the players in group $i$ without player $k: x_{-i k}^{*}=\left(x_{i 1}^{*}, \cdots, x_{i k-1}^{*}, x_{i k+1}^{*}, \cdots, x_{i n_{i}}^{*}\right)$. I obtain Proposition 2.

Proposition 2. If $v_{11}>v_{21}$, then (a) player 1 in group 2 announces the first period while player 1 in group 1 announces the second period, (b) free riders announce either the first or the second periods freely, (c) $x_{11}^{*}=x_{11}^{B 2}\left(x_{-11}, X_{2} ; v_{11}\right)$ and $x_{-11}^{*}=0$, and $(d) x_{21}^{*}=x_{21}\left(v_{11}, v_{21}\right)$, and $x_{-21}^{*}=0$.

The effort level of player 1 in group $i$ becomes the total effort levels of group $i$. Let $X_{i}^{*}$ denote the equilibrium total effort levels of group $i$ in the endogenous-timing framework, and let $X_{i}^{N}$ denote those of group $i$ in the simultaneous-move framework. As mentioned above, the favorite has the higher winning probability, whereas the underdog has the lower winning probability at the subgame-perfect equilibrium in the endogenous-timing framework. However, at Nash equilibrium in the simultaneous-move framework, the winning probability of the favorite is lower, whereas the winning probability of the underdog is higher [9] [14]. The change in the winning probability for active players leads to

${ }^{3}$ For concise exposition, I do not provide the full results with logit-form contest success functions. See also Baik and Shogren [9], Leininger [10], and Baik and Lee [12]. 
the changes in both groups' winning probabilities, $P_{1}\left(X_{1}^{*}, X_{2}^{*}\right)>P_{1}\left(X_{1}^{N}, X_{2}^{N}\right)$ and $P_{2}\left(X_{1}^{*}, X_{2}^{*}\right)<P_{2}\left(X_{1}^{N}, X_{2}^{N}\right)$. Furthermore, it directly affects the expected payoffs for free riders in both groups. Let $\pi_{i k}^{*}$ denote the equilibrium expected payoff of player $k$ in group $i$ in the endogenous-timing framework, and let $\pi_{i k}^{N}$ denote those of player $k$ in group $i$ in the simultaneous-move framework. Proposition 3 indicates the outcomes of the endogenous-timing framework and those of the simultaneous-move framework, respectively.

Proposition 3. If $v_{11}>v_{21}$, then I obtain (a) $X_{1}^{*}<X_{1}^{N}$ and $X_{2}^{*}<X_{2}^{N},(b)$ $P_{1}\left(X_{1}^{*}, X_{2}^{*}\right)>P_{1}\left(X_{1}^{N}, X_{2}^{N}\right)$ and $P_{2}\left(X_{1}^{*}, X_{2}^{*}\right)<P_{2}\left(X_{1}^{N}, X_{2}^{N}\right)$, (c) $\pi_{11}^{*}>\pi_{11}^{N}$ and $\pi_{1 f}^{*}>\pi_{1 f}^{N}$ for $f=2, \cdots, n_{1}$, and $(d) \pi_{21}^{*}>\pi_{21}^{N}$ and $\pi_{2 g}^{*}<\pi_{2 g}^{N}$ for $g=2, \cdots, n_{2}$.

Proposition 3 says that free riders in group 2 have the less expected payoffs, while free riders in group 1 have the greater expected payoffs in the endogenous-timing framework than in the simultaneous-move framework. Active players always obtain the advantage of exerting less effort in the endogenous-timing framework. At first glance, it seems to be more beneficial for all the players in group 2 to have the opportunity for choosing the period, because player 1 exerts less effort in the first period to take the strategic advantage and free riders naturally choose no effort even in both periods. Moreover, drawing on the literature on contest theory with regard to the public good, only the active player in each group plays a leading role, which carries the responsibility of winning; free riders, however, always seek to obtain positive externality without exerting effort to win against the other group.

Contrary to my expectation, only the free riders in group 2 suffer consequential damage in the endogenous-timing framework compared with the simultaneous-timing framework. In the endogenous-timing framework, the free riders in both groups treat their timing of moves as insignificant because winning the competition is directly related to player 1's effort. As they still exert no effort egoistically regardless of observing the player 1's positive effort level in the first period, which is less than his effort level in the simultaneous-move framework, the group 2's equilibrium total effort level becomes smaller and thus the winning probability for group 2 is less in the endogenous-timing framework than in the simultaneous-move framework. This egoistic behavior of free riders in group 2 leads to obtaining the low equilibrium expected payoffs, even though they have a choice to increase the group 2's total effort level. This is contrary to suggestions in the literature which demonstrate that the endogenous choice of timing must be beneficial and favorable for all players.

Andreoni [2] also shows that the sequential game succeeds to coordinate because of a large initial contribution, whereas the simultaneous game may fail to coordinate. However, in between-group competition, free riders in the group 2 can break with their group regardless of a positive effort in the first period, whereas all the players in group 1 agree to coordinate even though player 1 exerts a positive effort in the second period. In the endogenous-timing framework, the decision on the timing makes the egoistic behavior of free riders more severe 
and influences group 2 to dissolve more easily, compared with the simultaneous-move framework.

\section{Conclusions and Suggestions}

I have examined the two-group contest with the group-specific public-goods prize in the endogenous-timing framework, focusing not only on the equilibrium effort levels of players but also the equilibrium timing of their moves. I have shown that active players having the highest-valuation in each group play the strategic leading role, whereas the rest act as free riders, even in the endogenous-timing framework. I have also shown that active players choose their timing of moves strategically, while free riders decide on their timing of moves freely.

By comparing the equilibrium payoffs of the endogenous-timing framework with those of the simultaneous-move framework, I have shown that, unlike active players' equilibrium payoffs, free riders may have fewer equilibrium expected payoffs in the endogenous-timing framework. This is primarily because the decision on the timing makes the behavior of free riders more egoistically.

This paper has examined the players that independently and endogenously decide on their timing of moves. It would be interesting to consider endogenous group formation in which all of the players decide whether to join the group. I may expect that this can reduce the participation of free riders. This paper shows that free riders in the group with a lower-valuation active player are damaged by the independent choice of timing of moves. Thus, they are unwilling to participate in the contest.

\section{Acknowledgements}

I am grateful to Kyung Hwan Baik, Yong Gwan Kim, Dongwon Lee, Chong Kook Park and Dongryul Lee for their helpful comments and suggestions.

\section{References}

[1] Varian, H. (1994) Sequential Contributions to Public Goods. Journal of Public Economics, 53, 165-186. https://doi.org/10.1016/0047-2727(94)90019-1

[2] Andreoni, J. (1998) Toward a Theory of Charitable Fund-Raising. Journal of Political Economy, 106, 1186-1213. https://doi.org/10.1086/250044

[3] Romano, R. and Yildirim, H. (2001) Why Charities Announce Donations: A Positive Perspective. Journal of Public Economics, 81, 423-447. https://doi.org/10.1016/S0047-2727(00)00078-5

[4] Baik, K.H., Kim, I. and Na, S. (2001) Bidding for a Group-Specific Public-Good Prize. Journal of Public Economics, 82, 415-429. https://doi.org/10.1016/S0047-2727(00)00139-0

[5] Baik, K.H. (2008) Contests with Group-Specific Public-Good Prizes. Social Choice and Welfare, 30, 103-117. https://doi.org/10.1007/s00355-007-0226-3

[6] Lee, D. (2012) Weakest-Link Contests with Group-Specific Public Good Prizes. European Journal of Political Economy, 28, 238-248. https://doi.org/10.1016/j.ejpoleco.2011.11.003 
[7] Chowdhury, S., Lee, D. and Sheremeta, M. (2013) Top Guns May Not Fire: BestShot Group Contests with Group-Specific Public-Good Prizes. Journal of Economic Behavior and Organization, 92, 94-103. https://doi.org/10.1016/j.jebo.2013.04.012

[8] Kolmar, M. and Rommenswinkel, H. (2013) Contest with Group-Specific Public-Goods and Complementarities in Efforts. Journal of Economic Behavior and Organization, 89, 9-22. https://doi.org/10.1016/j.jebo.2013.02.006

[9] Baik, K.H. and Shogren, J. (1992) Strategic Behavior in Contests: Comment. American Economic Review, 82, 359-362.

[10] Leininger, W. (1993) More Efficient Rent-Seeking-A Münchhausen Solution. Public Choice, 75, 43-62. https://doi.org/10.1007/BF01053880

[11] von Stengel, B. (2010) Follower Payoffs in Symmetric Duopoly Games. Games and Economic Behavior, 69, 512-516. https://doi.org/10.1016/j.geb.2009.10.012

[12] Baik, K.H. and Lee, J.H. (2013) Endogenous Timing in Contests with Delegation. Economic Inquiry, 51, 2044-2055. https://doi.org/10.1111/j.1465-7295.2012.00487.x

[13] Dixit, A. (1987) Strategic Behavior in Contests. American Economic Review, 77, 891-898.

[14] Morgan, J. (2003) Sequential Contests. Public Choice, 116, 1-18. https://doi.org/10.1023/A:1024252514806

Submit or recommend next manuscript to SCIRP and we will provide best service for you:

Accepting pre-submission inquiries through Email, Facebook, LinkedIn, Twitter, etc. A wide selection of journals (inclusive of 9 subjects, more than 200 journals)

Providing 24-hour high-quality service

User-friendly online submission system

Fair and swift peer-review system

Efficient typesetting and proofreading procedure

Display of the result of downloads and visits, as well as the number of cited articles

Maximum dissemination of your research work

Submit your manuscript at: http://papersubmission.scirp.org/

Or contact tel@scirp.org 